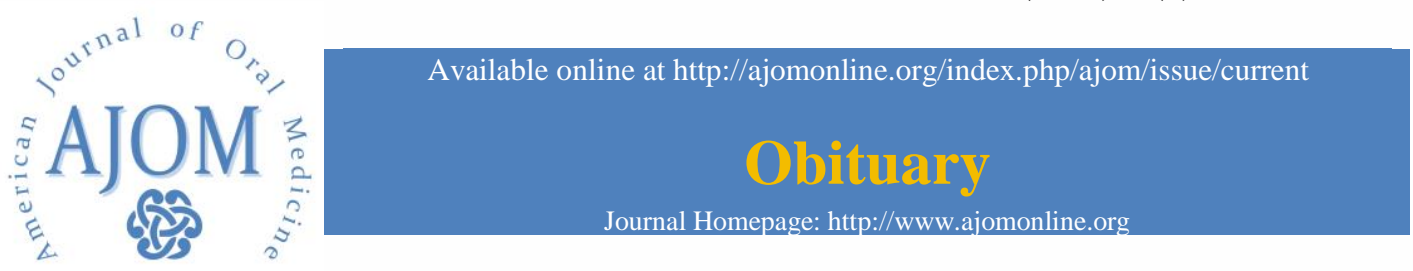

\title{
Obituary: Remembering Professor Dr Héctor Eduardo Lanfranchi Tizeira
}

\author{
Ana Mordoh $^{1}$, Mariana Gandolfo ${ }^{1}$, Claudia Giacco ${ }^{1}$
}

1 Oral Medicine Department, School of Dentistry, University of Buenos Aires, Argentina.

\section{PUBLICATION HISTORY}

Received: 26 June 2018 Accepted: 27 June 2018

Corresponding author: Ana Mordoh Oral Medicine Department School of Dentistry University of Buenos Aires Marcelo Torcuato de Alvear 2142, C1122AAH Buenos Aires, Argentina Tel: +54 (011) 4190-8231 fax: +54 (011) 4784-9110

E-mail: ana.mordoh@gmail.com

\section{OBITUARY}

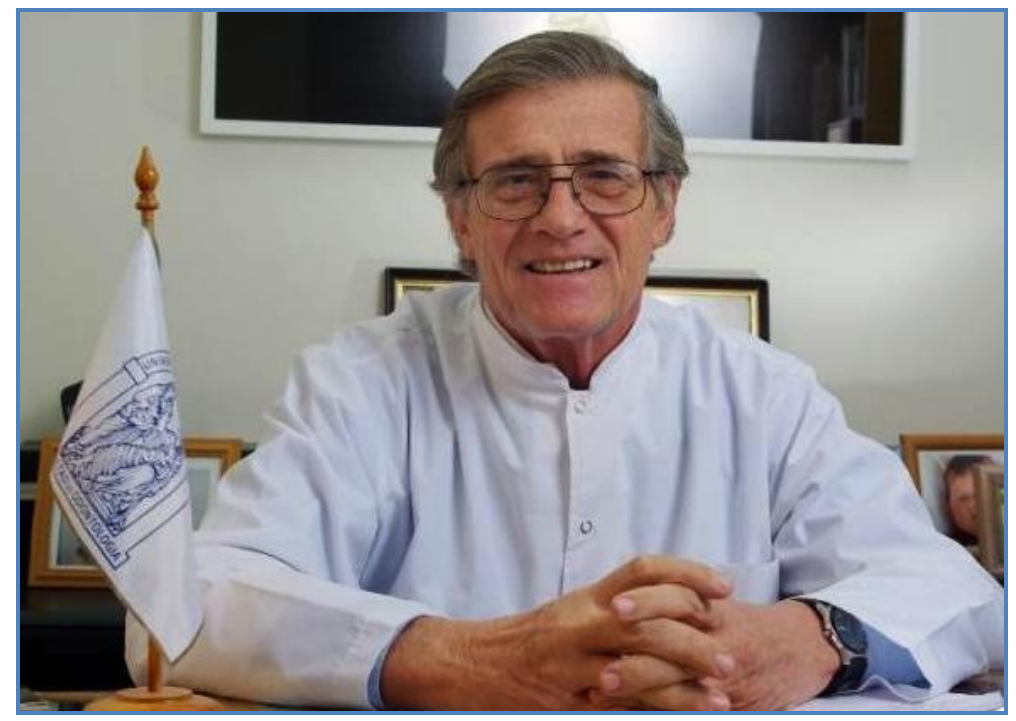

Professor Dr Héctor Eduardo Lanfranchi Tizeira, who sadly left us on January 25, 2017, was an example of a life deeply committed and devoted to teaching, to the care of his patients, to oral research and health education, as well as university management. He worked hard and selflessly to strengthen stomatology across the country and integrate Argentina with Latin America and the rest of the world. He held several executive positions, serving as President of the Argentine Division of the IADR in 1996.

Dr. Lanfranchi worked relentlessly for the integration of oral medicine teaching and practice across Latin America, and his efforts saw success in 2004 with the creation of the Latin American Federation of the International Association for Dental Research. He also played a decisive role in the creation of the Uruguayan Society of Dental Research. 
He was appointed Head Professor of the Department of Oral Medicine of the School of Dentistry of the University of Buenos Aires in 1991 and held the position until his passing. His highly productive work as teacher and researcher led to many publications in national and international peer reviewed journals, national and international scientific meetings, and graduate and post-graduate courses.

$\mathrm{He}$ worked enthusiastically training and developing human resources and helping his staff to advance in the profession, serving as thesis director to many Doctoral Fellows with the University of Buenos Aires, the National University of Córdoba, and the National University of Cuyo in Mendoza.

He served as Director of numerous research projects at prestigious institutions, as is the University of Buenos
Aires, and was the Director of the oral cancer prevention program "Stick your tongue out at cancer" of the International Association for Dental Research.

Dr. Lanfranchi was appointed Academician of the National Academy of Dentistry, Academician of the Academy of Medicine of Córdoba, Head of the Stomatology Program of the German Hospital of Buenos Aires, Honorary Professor of the National University of Córdoba, and Director of the School of Stomatology of the Argentine Circle of Dentistry.

The entire dental community will always remember our beloved Professor as one of our most outstanding academics, gifted with extraordinary capacity for work and intelligence, ready to share his expertise and experience, and devoted to creating interdisciplinary teams to provide all patients with the best quality care. 